[6] Syntheses of biazulenes coupled via the five-membered rings: R. Hagen, E. Heilbronner, P. A. Straub, Helv. Chim. Acta 51 (1968) 45; M. Pailer, H. Lobenwein, Monatsh. Chem. 102 (1971) 1558; T. Morita, K. Takase, Bull. Chem. Soc. Jpn. 55 (1982) 1144

[7] 6 [black crystals, m.p. $259-261^{\circ} \mathrm{C}$; IR (KBr): $1610,1595,1570 \mathrm{~cm}^{-1}{ }^{1}{ }^{1} \mathrm{H}$ NMR (250 MHz, $\left.\mathrm{CH}_{2} \mathrm{Cl}_{2}\right): \delta=4.27\left(\mathrm{~s}, 6 \mathrm{H}, 5-\mathrm{OCH}_{3}, 5^{\prime}-\mathrm{OCH}_{3}\right), 7.69$ (s, $\left.\left.2 \mathrm{H}, \mathrm{H}-12,12^{\prime}\right)\right]$ was synthesized from 1 by reduction with HI/HOAc, alkylation with $\mathrm{Me}_{2} \mathrm{SO}_{4} / \mathrm{NaOH}$, and subsequent oxidative coupling ( $\mathrm{FeCl}_{3} / \mathrm{DMF}$ ).

[8] Cf. also A. Tajiri, M. Fukuda, M. Hatano, T. Morita, K. Takase, Angew. Chem. 95 (1983) 911; Angew. Chem. Int. Ed. Engl. 22 (1983) 870; Angew. Chem. Suppl. 1983, 1283.

\section{Electrochemiluminescence of Tetrakis(diphosphonato)diplatinate(II)**}

\section{By Arnd Vogler* and Horst Kunkely}

Intermolecular photoredox reactions of electronically excited transition metal complexes with reducing or oxidizing agents have been the subject of intensive study in recent years ${ }^{[1]}$. The converse of such processes leads, under suitable conditions, to chemiluminescence $(\mathrm{CL})$. A special case is electrochemiluminescence (ECL). So far only a few investigations have been carried out on the $\mathrm{CL}^{[2]}$ or $\mathrm{ECL}^{[3]}$ of metal complexes, even though such studies provide important information on the mechanism of redox reactions; hitherto, such investigations have been restricted to complexes which contain 2,2'-bipyridyl or related ligands. The luminescent states are almost exclusively of the charge transfer (metal $\rightarrow$ ligand)-type. Herein we report on the $\mathrm{ECL}$ of $\left[\mathrm{Pt}_{2}\left(\mathrm{P}_{2} \mathrm{H}_{2} \mathrm{O}_{5}\right)_{4}\right]^{4 \ominus}\left(\mathrm{A}^{4 \ominus}\right)$. Both the associated redox processes as well as the ECL itself lead to changes in the metal-metal bonding in the binuclear platinum complex.

In $\mathrm{A}^{4 \ominus}$ the two $\mathrm{Pt}^{\prime \prime}$ centers are bridged by the dianions of the diphosphonic acid. The metal-metal interaction gives rise to the following series of MOs in order of increasing energy: $\quad 1 \mathrm{a}_{1 \mathrm{~g}}\left(5 \mathrm{~d}_{\mathrm{z}^{2}}\right)<1 \mathrm{a}_{\mathrm{zu}}\left(5 \mathrm{~d}_{z^{2}}\right)<2 \mathrm{a}_{1 \mathrm{~g}}\left(6 \mathrm{p}_{\mathrm{z}}\right)$ $<2 a_{2 u}\left(6 p_{z}\right)^{[4]}$. The $a_{1 g}$ orbitals are bonding and the $a_{2 u}$ orbitals are antibonding. In the ground state of $\mathrm{A}^{4 \Theta}\left(1 \mathrm{a}_{1 \mathrm{~g}}^{2} 1 \mathrm{a}_{2 \mathrm{u}}^{2}\right)$ the formal Pt-Pt bond order is therefore 0 . At room temperature and in solution, $\mathrm{A}^{4 \ominus}$ shows an intense photoluminescence of the lowest excited state $\left(1 \mathrm{a}_{1 \mathrm{~g}}^{2} 1 \mathrm{a}_{2 \mathrm{u}}^{1} 2 \mathrm{a}_{1 \mathrm{~g}}^{1}\right)$ with bond order $1^{[4]}$. Both a weak fluorescence $\left(\lambda_{\max }=407 \mathrm{~nm}\right)$ of the singlet ${ }^{1} \mathrm{~A}_{2 u}$ as well as an intense phosphorescence $\left(\lambda_{\max }=517 \mathrm{~nm}\right)$ of the accompanying triplet ${ }^{3} \mathrm{~A}_{2 \mathrm{u}}$ is observed ${ }^{[4]}$.

A 1-cm spectrophotometer cell fitted with two platinumfoil electrodes was used for the ECL investigations. Solutions of $\mathrm{A}^{4} \Theta$ as the tetrabutylammonium salt in oxygenfree anhydrous acetonitrile was subjected to an alternating current electrolysis with variable frequency (sine-wave generator, Kröncke Mod. 1246) using $n \mathrm{Bu}_{4} \mathrm{~N}^{\oplus} \mathrm{BF}_{4}^{\ominus}$ as supporting electrolyte. With an effective voltage of $4 \mathrm{~V}$ and frequency of $280 \mathrm{~Hz}$ and a current of $13 \mathrm{~mA}$, a marked green luminescence was observed at one electrode, even with the naked eye. The electrochemiluminescence (Fig. 1) in the long wave region was identical with the photophosphorescence, but no short-wave fluorescence could be observed.

[*] Prof. Dr. A. Vogler, Dr. H. Kunkely Institut für Anorganische Chemie der Universität Universitätsstr. 31, D-8400 Regensburg (FRG)

[**] This work was supported by the Deutsche Forschungsgemeinschaft and the Fonds der Chemischen Industrie. We thank Prof. H. B. Gray for helpful discussions and communication of unpublished results [6].

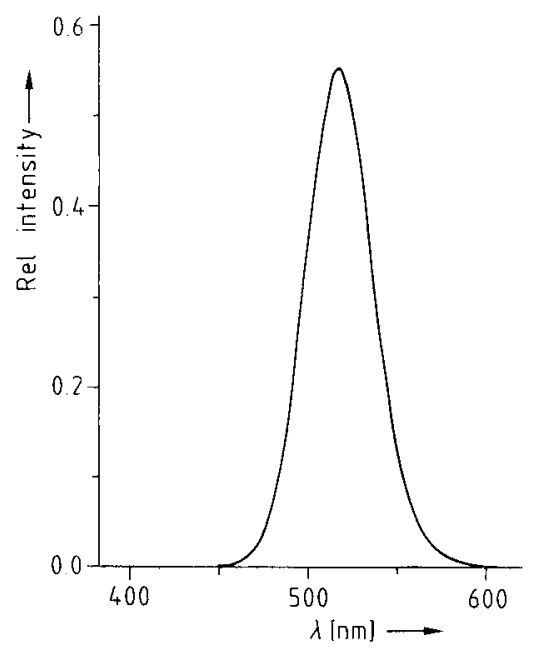

Fig. 1. Electrochemiluminescence spectrum of a solution of $2 \times 10^{-4} \mathrm{M}$ $\left(n \mathrm{Bu}_{4} \mathrm{~N}\right)_{4}\left[\mathrm{Pt}\left(\mathrm{P}_{2} \mathrm{H}_{2} \mathrm{O}_{5}\right)_{4}\right]$ and $0.1 \mathrm{M}\left(n \mathrm{Bu}_{4} \mathrm{~N}\right) \mathrm{BF}_{4}$ in $\mathrm{CH}_{3} \mathrm{CN}$; alternating current of $4 \mathrm{~V}$ and $280 \mathrm{~Hz}$.

From these observations we conclude that $A^{4 \ominus}$ is oxidized to $\mathrm{A}^{3 \ominus}$ during the anodic phase and reduced to $\mathrm{A}^{5 \ominus}$ during the cathodic phase. The recombination

$\mathrm{A}^{3 \ominus}+\mathrm{A}^{5 \ominus} \longrightarrow \mathrm{A}^{4 \ominus *}+\mathrm{A}^{4 \ominus}$

furnishes sufficient energy to generate one of the two product molecules in the lowest excited state, the triplet ${ }^{3} \mathrm{~A}_{2 \mathrm{u}}(*)$.

The $\mathrm{Pt}-\mathrm{Pt}$ bond is strengthened (bond order 1/2), both in the oxidation of $\mathrm{A}^{4 \ominus}$ to $\mathrm{A}^{3 \ominus}$ (ground state: $1 \mathrm{a}_{1 \mathrm{~g}}^{2} 1 \mathrm{a}_{2 \mathrm{u}}^{1}$ ) and the reduction to $\mathrm{A}^{5 \Theta}$ (ground state: $\left.1 a_{1 g}^{2} 1 a_{2 u}^{2} 2 a_{1 g}^{1}\right)$. On the other hand, the recombination involves both a bond-weakening $\left(\mathrm{A}^{4 \ominus}\right.$ in the ground state) and bond-strengthening $\left(\mathrm{A}^{4 \ominus}\right.$ in the excited state).

Since the ECL spectrum shows only the phosphorescence, and not the fluorescence, the potential difference between $\mathrm{A}^{3 \ominus}$ and $\mathrm{A}^{5 \ominus}$ is only sufficient to reach the lowest triplet ${ }^{3} \mathrm{~A}_{2 \mathrm{u}}(\approx 2.6 \mathrm{~V})$. The energy of the superposing singlet ${ }^{1} \mathrm{~A}_{2 u}(\approx 3.3 \mathrm{~V})$ is apparently not attained anymore.

The high frequency necessary for observation of the ECL would indicate that the oxidized $\left(\mathrm{A}^{3 \theta}\right)$ or reduced complex $\left(\mathrm{A}^{5 \theta}\right)$, or both, have a very short half-life. This has recently been confirmed: $\mathrm{A}^{3 \ominus}$ exists only in the solid state in the form of $\mathrm{Pt}_{2}$ chains which are bridged by halide $\mathrm{X}^{\ominus[5]}$; in solution $\mathrm{A}^{3 \ominus}$ immediately disproportionates into $\mathrm{A}^{4 \ominus}$ and $\mathrm{AX}_{2}^{4 \ominus} \cdot \mathrm{A}^{5 \ominus}$ was generated by pulse radiolysis, but rapidly disappeared $\left(k=2.9 \times 10^{4} \mathrm{~s}^{-1}\right)^{[6]}$. It is therefore understandable that it was not possible to determine the redox potentials for the reversible one-electron process by cyclovoltammetry. On attempting to quench the photoluminescence of $\mathrm{A}^{4 \ominus}$ by electron donors and acceptors, it was however possible to estimate the redox potentials. Donors such as $N, N$-dimethylaniline $\left(E_{1 / 2}=0.78 \mathrm{~V}\right.$ vs SCE) and $N, N$-dimethyl-p-toluidine $\left(E_{1 / 2}=0.65 \mathrm{~V}\right)$ could not quench the photoemission of $\mathrm{A}^{4 \ominus}$. Even the strong reducing agent $N, N, N^{\prime}, N^{\prime}$-tetramethyl-p-phenylenediamine $\left(E_{1 / 2}=+0.24 \mathrm{~V}\right.$ vs SCE) did not effect reduction of $\mathrm{A}^{4 \ominus}$ in the ${ }^{3} \mathrm{~A}_{2 \mathrm{u}}$ state. It follows, therefore, that the reduction of $\mathrm{A}^{4 \ominus}$ in the ground state requires at least $E_{1 / 2}=-2.3 \mathrm{~V}$ vs SCE. In contrast, the phosphorescence of $\mathrm{A}^{4 \Theta}$ is quenched by relatively weak acceptors ${ }^{[7]}$. It is estimated that the oxidation of $\mathrm{A}^{4 \ominus}$ takes place at potentials of less than $E^{0}=+1.6 \mathrm{~V}$ vs NHE. The alternating potential of $4 \mathrm{~V}(2 \mathrm{~V}$ 
cathodic and $2 \mathrm{~V}$ anodic) necessary for observation of the ECL is needed for the reduction of $\mathrm{A}^{4 \ominus}$, whereas smaller potentials should suffice for the oxidation.

Received: July 13, 1983; revised: February 27, 1984 [Z 466 IE] German version: Angew. Chem. 96 (1984) 299

CAS Registry number:

$\left(n \mathrm{Bu}_{4} \mathrm{~N}\right)_{4}\left[\mathrm{Pt}_{2}\left(\mathrm{P}_{2} \mathrm{O}_{5} \mathrm{H}_{2}\right)_{4}\right], 89462-52-2$

[1] V. Balzani, F. Bolletta, M. T. Gandolfi, M. Maestri, Top. Curr. Chem. 75 (1978) 1; T. J. Meyer, Acc. Chem. Res. 11 (1978) 94; D. G. Whitten, ibid. 13 (1980) 83; N. Sutin, ibid. 15 (1982) 275.

[2] A. Vogler, L. El-Sayed, R. G. Jones, J. Namnath, A. W. Adamson, Inorg. Chim. Acta 53 (1981) L35; A. Vogler, H. Kunkely, Angew. Chem. 93 (1981) 470; Angew. Chem. Int. Ed. Engl. 20 (1981) 469; V. Balzani, F. Bolletta, J. Photochem. 17 (1981) 479, and references cited therein.

[3] I. Rubinstein, A. J. Bard, J. Am. Chem. Soc. 103 (1981) 512, and references cited therein; F. Bolletta, M. Ciano, V. Balzani, N. Serpone, Inorg. Chim. Acta 62 (1982) 207.

[4] W. A. Fordyce, J. G. Brummer, G. A. Crosby, J. Am. Chem. Soc. 103 (1981) 7061; S. F. Rice, H. B. Gray, ibid. 105 (1983) 4571.

[5] C.-M. Che, F. H. Herbstein, W. P. Schaefer, R. E. Marsh, H. B. Gray, J. Am. Chem. Soc. 105 (1983) 4604.

[6] C.-M. Che, S. J. Atherton, L. G. Butler, H. B. Gray, private communication.

[7] C.-M. Che, L. G. Butler, H. B. Gray, J. Am. Chem. Soc. 103 (1981) 7796.

\section{$\mathrm{Na}_{3} \mathrm{P}_{21}$ and $\mathrm{Li}_{3} \mathrm{P}_{21}$, the First Polyphosphides with Isolated $\mathbf{P}_{21}^{3-}$ Groups* *}

By Marianne Baudler*, Doris Düster, Klaus Langerbeins, and Joachim Germeshausen

We recently reported on the synthesis of the polyphosphides $\mathrm{Li}_{3} \mathrm{P}_{7}{ }^{[1]}$ and $\mathrm{Li}_{2} \mathrm{P}_{16}{ }^{[2]}$ by nucleophilic cleavage of white phosphorus with lithium dihydrogen phosphide. Salts containing isolated $\mathrm{P}_{\mathrm{n}}^{\mathrm{m}-}$ anions are of current interest because of their structural relationship with the phosphorus hydrides $P_{n} H_{m}$ and organophosphanes $P_{n} R_{m}$ and because of their potential use as building blocks for the synthesis of novel polyphosphorus compounds. Herein we report on the synthesis of a trisodium henicosaphosphide and a trilithium henicosaphosphide containing isolated $\mathrm{P}_{21}^{3-}$ groups.

$\mathrm{Na}_{3} \mathrm{P}_{21} \mathbf{1}^{[3]}$ is formed on reaction of white phosphorus with substoichiometric amounts of sodium in 1,2-dimethoxyethane or tetrahydrofuran (THF). Other products of the reaction include $\mathrm{Na}_{2} \mathrm{P}_{16}{ }^{[4]}, \mathrm{Na}_{2} \mathrm{HP}_{7}{ }^{[4]}$, and further, as yet unidentified polyphosphides. The product pattern is strongly dependent on the reaction conditions: The best crude yield of 1 (up to $75 \mathrm{P}-\%$ of the soluble reaction products) is obtained at a $\mathrm{P}: \mathrm{Na}$ ratio of $2: 1$ (not $7: 1$ !) in boiling THF. $\mathrm{Na}_{3} \mathrm{P}_{21} \cdot 15 \mathrm{THF}$, a solvent adduct of 1 , can be isolated analytically pure by crystallization at $-20^{\circ} \mathrm{C}$. On drying, the orange needle-shaped crystals lose a part of the solvent of crystallization with concomitant decomposition to $\mathrm{Na}_{2} \mathrm{P}_{16}$ and other polyphosphides. Above $-10^{\circ} \mathrm{C}$ liquefaction occurs, whereas at room temperature slow disproportionation takes place. The henicosaphosphide is only slightly sensitive to oxidation but strongly sensitive to hydrolysis.

[*] Prof. Dr. M. Baudler, D. Düster, Dr. K. Langerbeins, J. Germeshausen Institut für Anorganische Chemie der Universität Greinstrasse 6, D-5000 Köln 41 (FRG)

[**] Contributions to the Chemistry of Phosphorus, Part 141. This work was supported by the Deutsche Forschungsgemeinschaft and the Fonds der Chemischen Industrie.--Part 140: M. Baudler, R. Heumüller, K. Langerbeins, Z. Anorg. Allg. Chem., in press.
$\mathrm{Li}_{3} \mathrm{P}_{21} \mathbf{2}$ is formed as main product on reaction of $\mathrm{Li}_{3} \mathrm{P}_{7}{ }^{[1,5]}$ with iodine or 1,2-dibromoethane as well as on metalation of $\mathrm{P}_{7} \mathrm{H}_{3}{ }^{[5]}$ with lithium dihydrogen phosphide or $n$-butyllithium under suitable reaction conditions ${ }^{[6]} .2$ is also formed on decomposition of $\mathrm{LiH}_{2} \mathrm{P}_{7}{ }^{[7]}$ and $\mathrm{Li}_{2} \mathrm{HP}_{7}{ }_{7}^{[7]}$ at room temperature and on nucleophilic cleavage of white phosphorus ${ }^{[8]}$. Because of the similarity to 1 we have not isolated 2.

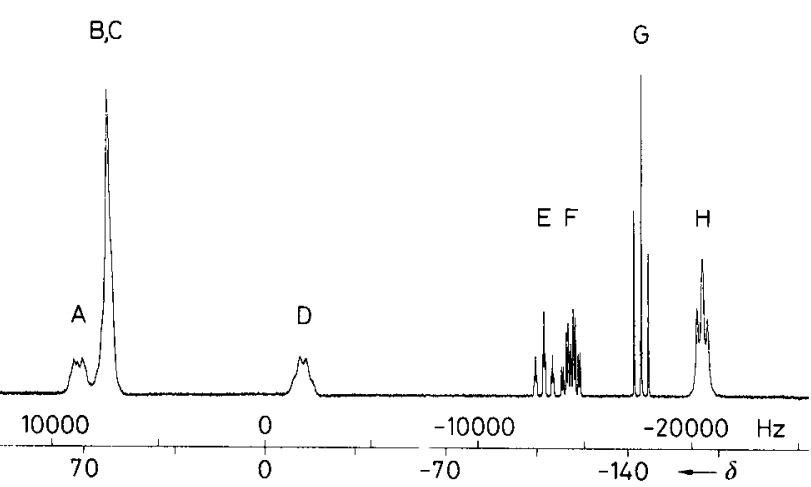

Fig. 1. ${ }^{31} \mathrm{P}-\mathrm{NMR}$ spectrum of $\mathrm{Na}_{3} \mathrm{P}_{21}$ in tetrahydrofuran/dimethylformamide (ca. $2: 1)$ at $243 \mathrm{~K}(121.497 \mathrm{MHz})$.

1 and 2 show identical ${ }^{31} \mathrm{P}$-NMR spectra, in which seven groups of signals occur at $\delta=+72,+61,-15$, $-108,-118,-146$ and -169 (intensity ratio $2: 8: 2: 1: 2: 2: 4$ ) (Fig. 1). The number and intensities of the groups indicate a symmetrical $P_{21}$ skeleton. On the basis of their splitting patterns, chemical shifts and relative

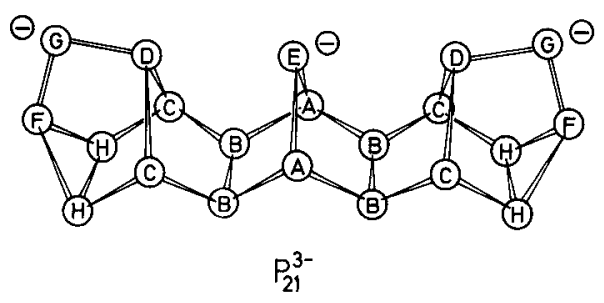

intensities the signal groups D, F, G, and $\mathrm{H}$ are each to be assigned to five $\mathrm{P}$ atoms from two equivalent $\mathrm{P}_{7}$ cages with nortricyclene structure ${ }^{[\mathcal{P}]}$. As evidenced by the triplet-like signal group $\mathrm{E}$, a $\mathrm{P}_{7}$-substructure analogous to norbornane with negative charge on the $P$ atom of the $P_{1}$-bridge is present as linkage between the two cages. Correspondingly, from the intensities of the remaining signals it follows that the downfield group $\mathrm{A}$ arises from the two central bridgehead atoms ${ }^{110]}$, while the neighboring intense signal $B, C$ arises from the remaining two pairs of four equivalent $\mathbf{P}$ atoms.

The constitution of the $\mathbf{P}_{21}^{3-}$ ion as decacyclo$\left[9.9 \cdot 1 \cdot 0^{2,10} \cdot 0^{3,7} \cdot 0^{4,9} \cdot 0^{6,8} \cdot 0^{12,20} \cdot 0^{13,17} \cdot 0^{14,19} \cdot 0^{16,18}\right.$ ]henicosaphosphide( $3-$ ) is confirmed by the homoscalar-correlated $2 \mathrm{D}$ ${ }^{31}$ P-NMR spectrum (COSY spectrum ${ }^{[1]}$ ) of 1 (Fig. 2). All ${ }^{1} J(\mathrm{PP})$ couplings of the directly linked and non-degenerated $\mathrm{P}$ atoms appear as cross-peaks.

The $P_{21}^{3-}$ ion is the largest isolated $P_{n}(m)$ unit group known so far. In $\mathrm{K}_{4} I \mathrm{P}_{21}$ synthesized by von Schnering et al. ${ }^{[12]}$ these $\mathrm{P}_{21}^{3-}$ groups are linked, after opening of their three-membered rings, to give a polymeric ${ }_{\infty}^{2}[\mathrm{P} 7]$-structure. As a conjuncto-phosphane the isolated $\mathrm{P}_{21}$ (3) skeleton is made up of a $\mathrm{P}_{7}(5)$ unit analogous to 